\title{
ANALYSTS' RECOMMENDATIONS AND THE MARKET IMPACT OF THE VALUATION METHODS
}

\author{
Elisa Cavezzali *, Enrico Maria Cervellati *, Pierpaolo Pattitoni ${ }^{* *}$, \\ Ugo Rigoni
}

* Department of Management, Ca' Foscari University of Venice, Italy

** Department of Statistical Sciences "Paolo Fortunati”, University of Bologna, Italy; Rimini Centre for Economic Analysis, Canada *** Corresponding author, Department of Management, Ca' Foscari University of Venice, Italy Contact details: Ca' Foscari University of Venice, Fondamenta San Giobbe 873 Cannaregio - 30121 Venice, Italy

\section{OPEN ACCESS}

How to cite this paper: Cavezzali, E., Cervellati, E. M., Pattitoni, P., \& Rigoni, U. (2019). Analysts' recommendations and the market impact of the valuation methods. Journal of Governance \& Regulation, 8(4), 46-55.

https://doi.org/10.22495/jgrv8i4art4

Copyright (c) 2019 The Authors

This work is licensed under a Creative Commons Attribution 4.0 International License (CC BY 4.0).

https://creativecommons.org/licenses/by/ $4.0 /$

ISSN Print: 2220-9352

ISSN Online: 2306-6784

Received: 13.10 .2019

Accepted: 20.12.2019

JEL Classification: G14, G24, M4

DOI: 10.22495 /jgrv8i4art4

\begin{abstract}
Despite its importance, the informative value of the analysts' valuation methods has not been thoroughly examined in the literature. Such an issue is relevant with regard to the concerns on analysts' objectivity. We test whether investors' reaction is jointly influenced by recommendations and target revisions and mainly by valuation method used because it summarizes the information considered to be relevant by the analysts. We analyse the market reaction to recommendation revisions with an event study methodology, calculating marketadjusted abnormal returns at the report release date. We run regressions to test the market impact of recommendations and target price revisions, as well as their interaction, and we then focus on testing several models to discern market reaction to distinct valuation methods. We show that market reaction is influenced by the valuation methods used in their reports. The majority of previous studies relying on commercial databases report the market reaction in relation to analysts' recommendations, target prices or earnings forecasts, often overlooking the content of the reports and the methodology used therein. This is due to an information constraint of commercial databases, normally including only the above-mentioned synthetic variables. A notable exception is Asquith, Mikhail, and Au (2005) who find no relation between the market reaction and the valuation methods used by analysts. Compared to Asquith et al. (2005), our research uses a larger database and finds a different result. We show the market reacts differently to distinct valuation methods, without favouring the theoretically more correct ones based on discounting cash flows. We also find that the market reaction is larger when the analysts support their recommendation with more than one valuation method. Our research shows that the market pays attention to the content of the reports and analysts can be more influential when they use more valuation methodologies to cross-check their estimates.
\end{abstract}

Keywords: Equity Analysts, Valuation Methods, Market Reaction, Content Analysis, Event Study

Authors' individual contribution: Conceptualization - E.C., E.M.C., P.P., and U.R.; Methodology - E.C., E.M.C., P.P., and U.R.; Formal Analysis - E.C., P.P., and U.R.; Resources - E.C., E.M.C., P.P., and U.R.; Data Curation E.C., P.P., and U.R.; Writing - Original Draft - E.C., E.M.C., P.P., and U.R.; Writing - Review \& Editing - E.C., E.M.C., P.P., and U.R.; Visualization E.C., E.M.C., P.P., and U.R.; Supervision - E.C., E.M.C., P.P., and U.R.; Project Administration - E.C., E.M.C., P.P., and U.R.; Funding Acquisition E.M.C.

\section{INTRODUCTION}

In an efficient market, stock prices should discount all available information, indicating to investors the expected return on their investments. In the real world, the stock market is seldom efficient, and investors need to improve their information set paying for information elaboration services, such as 
those provided by financial analysts. Sell-side financial analysts convey information to the market issuing research reports on the stocks they follow. Analysts use their skills to process, through one or more evaluation methods, the information that companies provide them into firm valuations, which, when compared to the current price, result in a justifiable stock recommendation released to investors.

Financial analysts use a wide set of techniques for their researches and to make recommendations The reports they issue are then used by investors in their decision-making process. Thus, in a widely accepted perspective, analysts are important information intermediaries in the capital markets.

Despite their importance, however, the informative value of the analysts' valuation methods has not been thoroughly examined in the literature. Such a research issue is relevant, however, especially following the recent financial scandals, the usual concerns about the objectivity of analysts, as well as the scepticism about their researches, such a research issue is important. Our analysis tackles this issue testing whether the investors' reaction is jointly influenced both by recommendations and target revisions and by other important elements contained in the reports, primarily the valuation method. In our perspective, the valuation methods used can be an additional informative signal for the market as it summarizes the information considered as value relevant by the analysts. Thus, we expect that investors' reaction will differ in correspondence to the different combination of recommendations and target prices revisions and valuation methods used.

Thus, our research hypothesis is the following: Is the valuation method used by sell-side analysts important as reflected in a distinct market reaction?

The greatest part of earlier research on financial analysts is based on commercial databases (e.g., Factset, I/B/E/S, JCF First Call, Thomson Financial, Zacks, etc.) providing just a small proportion (earnings forecasts, target prices and recommendations) of the overall information that is included in a report. As a consequence, many prior studies in the literature describe how investors react to the synthetic information provided in the reports (recommendations and target prices) or to the earnings forecasts (e.g., Womack, 1996; Mikhail, Walther, \& Willis, 1997; Gleason \& Lee, 2000; Gleason, Johnson, \& Li, 2012; Bonini, Zanetti, Bianchini, \& Salvi, 2010; Kerl, 2011; Bonini \& Kerl, 2012; Bilinski, Lyssimachou, \& Walker, 2013; Bradshaw, Brown, \& Huang, 2012; Hashim \& Strong, 2018).

As a matter of fact, few papers (e.g., Asquith et al., 2005; Demirakos, Strong, \& Walker, 2010; Gleason et al., 2012) analysed the relationship between valuation methods and target price accuracy, but their results appear to be inconclusive and somehow contradictory.

In particular, Asquith et al. (2005) investigate the association between market returns and the content of analyst reports. Their analysis uses a set of about 1,100 reports issued by members of the Institutional Investor All-American Research Team, from 1997 to 1999 . Their findings show that there is no correlation between the specific kind of valuation methodology used by analysts and the market reaction. This research, however, shows some evident drawbacks related to the reports' selection, causing a selection bias in the analysis. First, the authors concentrate their analysis just on celebrity analysts, excluding the others. Second, they collect the reports from Investext, a commercial database collecting only those reports that investment banks are willing to make publicly available. Thus, the sample does not include the reports of famous and market-relevant investment banks, such as Goldman Sachs. Finally, their research is based on a limited three-year time horizon, not allowing a wider perspective of the analysis.

Our paper addresses these drawbacks, providing new evidence. Our analysis is based on a broader dataset of reports issued by all the analysts following Italian listed companies, over a wide time range of ten years, from 1999 to 2009. Such a longtime horizon allows us to collect a huge amount of data and therefore to perform a richer analysis compared to previous studies in the literature.

The only way to analyse the content of the reports and, in particular, the valuation methods used by the analysts is to read the text of the reports and to code the content by hand. As analysts' reports are not usually available to the general public of investors and commercial datasets are not exhaustive, we needed an alternative database to answer our research questions. In this respect, Italy represents an advantageous and unique ${ }^{1}$ research setting since a mandatory rule imposes to all the investment banks issuing reports on firms listed on the Italian stock exchange to submit them to the Security and Exchange Commission, the Consob, and to the managing company of the stock exchange, Borsa Italiana. While analysts have to send their reports on the very day of issuance to Consob, they have to send it to Italian stock exchange within sixty days. Once received the reports, Borsa Italiana has to immediately publish them on its website. Thereafter, they become freely available to the generality of investors. We collect about 25,000 reports covering more than 200 companies listed on the Italian stock exchange over a time period of almost ten years (from September 1999 to April 2009). We focus on almost 3,000 recommendation changes issued by about 50 brokers on more than 200 firms. We read carefully the full text of these reports and catalogued by hand both the summary measures and, whenever possible, the additional information related to the valuation methods used. ${ }^{2}$ To assess the informative value of analysts' valuation methods, we perform an event study, testing several models.

Our results differ from the empirical evidence found by Asquith et al. (2005). First, we find a "method effect". Specifically, we show that the market reacts differently to distinct types of valuation methods, without privileging one of them. At odds with the finance theory, stating the conceptual superiority of the methods based on the discounted cash flows, compared to alternative approaches, the market does not seem to follow this hierarchy. In the case of a downgrade, financial and net asset-based methods have a greater impact on the market if compared to the method using market ratios. Mixed ${ }^{3}$ methods and income-based methods do not have any statistically significant effect. For upgrades, instead, while the latter two methods remain not significant, the market ratios are

\footnotetext{
As far as we know, the Italian regulatory system on financial analysts in unique in the world.

2 It took us about two years to complete the collection and the analysis of all the took us about iwo years to comple the collection al relevant information

3 By "mixed" method, we mean methods using both balance sheet and income statement variables (Fernandez, 2007).
} 
associated with the larger market reaction when compared to the financial and net asset-based methods. Furthermore, as a consequence of the previous findings, we also find a "cross reinforcing methods effect", i.e., we show a larger market reaction in correspondence to analysts' use of several methods to assess the company value. This suggests that the market trusts more analysts relying on more than one method to support their recommendations.

The remainder of the paper is organized as follows: Section 2 provides a review of the literature; Section 3 describes the dataset; Section 4 outlines the sample selection procedures and the methodology used; Section 5 reports the empirical results and Section 6 concludes the paper.

\section{LITERATURE REVIEW}

Prior research indicates that sell-side analysts are important information intermediaries in capital markets (Cervellati, Della Bina, \& Pattitoni, 2007a, 2007b, 2008; Cervellati, 2012; Cervellati \& Piras, 2012; Piras, Denti, \& Cervellati, 2012; Hansen, 2015; Hobbs \& Singh, 2015; Brown, Call, Clement, \& Sharp, 2014, 2015; Kucheev \& Sorensson, 2016; Merkley, Michaely, \& Pacelli, 2017a, 2017b; Yin, Peasnell, \& Hunt, 2016).

Regulators and market participants view analysts and the competition among them as enhancing the informational efficiency of market prices. Furthermore, analysts' activity is important to investors to form their expectations about firms' earnings and making investment decisions based on their recommendations (Hodge, 2003; Williams, Moyes, \& Park, 1996). Frankel, Kothari, and Weber (2006) argue that financial analysts' reports are "price informative".

Reports' information value rises when volatilities, volumes and returns increase. Reports appear to be more effective when there is bad news rather than good news. The short-term reaction is subsequently not inverted, showing that investors neither over-react nor under-react. Womack (1996) examines the price reaction to recommendation changes, highlighting that added-to-buy and addedto-sell revisions, representing extreme changes, record a greater market reaction. Lys and Sohn (1990) show that analysts' forecasts are price informative, even when preceded by other types of disclosures, including forecast revisions issued by other analysts.

Francis and Soffer (1997) find that neither earnings forecast revisions nor stock recommendations completely incorporate the information of other signals. They also show that when a report is summarized by a favourable stock recommendation, investors rely on earnings forecast revisions.

Jurgens (2000) finds the recommendations to affect not only daily stock returns but also the intraday ones, also taking into account potential confounding effects like the contemporary release of other news. The author argues that analysts' information is by far more effective compared to public news.

Gleason and Lee (2000) detect a persistent price drift over the two years following earnings revisions.

Dittmar, Kaul, and Lei (2007) suggest that these drifts reflect a behavioural under-reaction to the information contained in the revisions.
Elgers, Lo, and Pfeiffer (2001) find a delayed price reaction in correspondence of analysts' disclosure on their earnings forecasts or their valuation of the covered company. The delayed reaction is bigger both when the analysts' coverage is low and in the quarter following the earnings announcement.

Brav and Lehavy (2003) provide evidence that investors perceive analysts' target prices as signals regarding the company's value. The authors investigate whether the market reaction to target price revisions is sensitive to recommendations downgrade, upgrade or reiterations. Their findings show that target prices are informative both unconditionally and conditionally on simultaneous recommendations and earnings forecast revisions.

As briefly mentioned in the introduction, the Italian market is a peculiar case because of its "double-date" system. The two relevant dates are the so-called "report date", i.e. the one written on the report and supposedly the one in which the report has been prepared for the analyst's private clients and the "public access date" when the report is made freely and publicly available to all investors on the Italian stock exchange website.

Belcredi, Bozzi, and Rigamonti (2003) find significant abnormal returns and volumes on the event day, with an anticipated market reaction before the report date. Using the same source of data, but a larger number of reports (more than 22,000 ) on a longer period of time (from September 1999 to July 2005), Cervellati et al. (2007a) reexamine the market reaction to the recommended changes for the Italian case. The authors confirm previous results, but they also investigate the determinants of cumulative abnormal returns like analysts' experience, firm and broker size.

Bradshaw et al. (2012) report a high level of target price accuracy, while previous studies (e.g., De Vincentiis, 2010; Kerl, 2011; Bilinski et al., 2013) show that target prices are only partially accurate.

Valuation methods used by analysts are typically classified into two macro-classes (Gleason et al., 2012): single-period valuation methods (e.g., market multiples), and multi-period valuation methods (e.g., Discounted Cash Flow (DCF) and Residual Income Methods (RIM).

However, few studies (e.g., Asquith et al., 2005; Demirakos et al., 2010; Gleason et al., 2012) analyse how valuation methods do affect forecast accuracy, but their results appear to be inconclusive and somehow contradictory.

In particular, Asquith et al. (2005) demonstrate that other information, such as the justifications that analysts use in support of their point of view, is also important and if incorporated in the analysis reduces, and in some cases eliminates, the significance of the information available in earnings forecasts and recommendation revisions. Their analysis also controls for the simultaneous release of information showing that analysts' reports convey new and independent analysis to the market. By examining whether the market reaction differs by report type (i.e., upgrade, reiteration, or downgrade), the authors show that the report information is more important for downgrades than for upgrades. However, they don't find any market reaction to the valuation methods used by the analysts.

Our paper addresses the above-mentioned drawbacks, extending previous studies and providing new evidence. 


\section{DATA DESCRIPTION}

Differently from previous studies based on commercial datasets, we collect data directly from the text of the actual financial analysts' reports. This procedure allows us to catalogue a rich set of information usually not included in other datasets.

Commercial datasets used in previous studies (e.g., Womack, 1996; Mikhail et al., 1997; Gleason \& Lee, 2000; Kerl, 2011; Bilinski et al., 2013; Bradshaw et al., 2012; Hashim \& Strong, 2018) catalogue just a small part (mainly earnings forecasts, recommendations and target prices) of the information included in the reports. The valuation methods can be usually found just trough a deep and comprehensive analysis and interpretation of the reports. We have read and catalogued by hand all the 25,422 reports available on the website of Borsa Italiana S.p.A. from September 1999 to April 2009, issued by domestic and foreign banks and brokerage houses covering the companies listed in the Italian stock exchange. Considering only the reports that present recommendation changes, the final dataset includes 2,811 revisions $(1,481$ downgrades and 1,330 upgrades), issued by 57 brokers on 226 companies. We evidence that the market of financial reports is highly concentrated both on the broker and the covered firm side. In our sample, ten percent of the more active intermediaries produce about $50 \%$ of the studies. Furthermore, the first ten percent of the covered companies - that is also the biggest in terms of market capitalization - receive about $40 \%$ of the studies.

We collected many kinds of information both at analyst-level and at report-level. Specifically, our dataset includes analyst' and broker's identity, report date, investment recommendations, target prices and evaluation methods used. Some of the data were easy to identify while others needed a further reclassification. In particular, the correct identification and classification of the evaluation methods used by analysts was complex.

Differently from Asquith et al. (2005), in the reports we analyse, the analysts seldom explicate the specific valuation methods used. Furthermore, they often combine different methods and approaches; they create new valuation techniques or personalize existing ones, probably to better fit them to the characteristics of the analysed companies. This forced us to deduce, whenever possible, the methods from the reports. We built a structured framework to capture the variety of techniques used by analysts and to reduce the several (and more/less sophisticated) procedures to some known valuation methods.

Initially, we started from the theoretical ranking proposed for the valuation methods by the majority of the finance textbooks, identifying the following five classes of methods: net assets, financial, earnings-based, mixed, market ratios. However, during our empirical work, we encountered several valuation methods and we needed to add some specifications for each class.

Frequently, the analysts use some low-cost simplifications of the traditional techniques leading to quick and less accurate value estimates than the full implementation of the original models. For instance, in the net asset methods we included the Net Asset Value approach $(N A V)$, the Embedded Value $(E V)$ and the Appraisal Value $(A V)$ methods. We classify as "income-based method" the Discounted Shareholder Profit (DSP), the Discounted Earnings $(D E)$, but also other heuristic methods. Among these heuristic methods, one is based on the ROIC index, another one is named Warranty Equity Valuation $(W E V)$ and, finally, one is called Required ROE $(R R)^{4}$ We called "financial method": the Dividend Discounted Model $(D D M)$ and the Discounted Cash Flows $(D C F)$ model, the Gordon Growth Model $(G G M)$, the Adjusted Present Value $(A P V)$ model and a particular model based on the discounting of cash flows and used by just a small number of brokers, called HOLT-CFROI. ${ }^{5}$ We named as "mixed models" the EVA and the Regulatory Asset Based methods $(R A B)$, particularly used by the energy companies to estimate the value of the net invested capital. With regard to the market ratio methods, we included both the approaches of the comparable companies and the deals multiple. ${ }^{6}$

We analyse in detail and catalogue in one of the five methods categories presented above also several methods unnamed by the analysts. Furthermore, since analysts often adopt at the same time two or more methods, whenever possible, we try to identify the main one, that is, the valuation method which the final recommendation relies on more.

All the methods not explicitly defined or indicated as "primary" have been classified as "secondary". Since we refer to the original analysts" recommendations, we use caution in the classification of their changes. We only consider upgrades or downgrades with respect to the previous recommendation, since previous studies (Stickel, 1992, 1995) document more significant reactions in case of revisions than in case of reiterations. This evidence is due to the greater information conveyed by a recommendation change compared to a reiteration that is less informative for the market.

\section{RESEARCH DESIGN AND METHODOLOGY}

To assess the informative value of analysts' reports, we focus on the market reaction to recommendation revisions. In order to perform our event study, we first calculate the market reaction to recommendation changes for each firm in our dataset. We indicate the market reaction as the percentage market-adjusted abnormal returns, ARs, at the report release date. We consider marketadjusted returns to take into account the systematic component in stock returns. ${ }^{7}$ Then, we use ARs as the response variable in our regression analysis.

We first run some regressions testing specifically the market impact of recommendations and target price revisions, as well as their interaction. Thus, we include among the regressors some dummy variables representing recommendation and target price downgrades ( $\mathrm{Rd}$ and TPd respectively), and upgrades ( $\mathrm{Ru}$ and $\mathrm{TPu})$. This preliminary analysis allows us to compare our dataset characteristics

\footnotetext{
${ }^{4}$ Warranty equity valuation method establishes that the value of equity $(E)$ is given by the formula: $E=(R O E-g) /(C O E-g) * P / B V$, where $R O E$ is the return on equity, $g$ is long term growth rate of earnings, $C O E$ is the cost of equity and $P / B V$ is price to book value. $R O E$ required is the same of $W E V$, but in case of no growth, i.e. when $g$ is equal to zero.

5 Cash Flow Return on Investment (CFROI) is a cash flows-based valuation framework, originally developed in 2002 by HOLT Value Associates.

In the comparable companies' approach, the company estimated value stems from the data resulting from the stock prices on a fully representative and comparable sample of companies listed and traded on regulated markets. Differently, in the deals multiple, the data are collected by the negotiations occurred outside the market formally recognized. The price per share can be seen from the results of the sale.

To take into account the systematic component in stock returns, we follow Asquith et al. (2005) who simply take the difference between the stock and the market return at the report date. However, more sophisticated models can the market return at the report date. However, more sophisticated models can be used to assess abnormal returns. Thus, as a robustness check, we use the market model to determine expected returns. Coherently with previous findings in the literature on short term event studies (Campbell, Lo, \& mocki, letting the qualitative interpretation of results unchanged.
} 
with the ones used in previous studies, and to highlight similarities or differences in the market reaction following analysts' revisions with respect to the main findings in the literature. Performing this analysis is essential since we focus on the specific case of the Italian stock exchange that could offer different empirical evidence than those documented in studies concerning other markets. As a further step in the analysis, we test whether the short-term market reaction following a recommendation change is related to the strength of the revision. To do this, we add to our regression models two dummy variables, AtS and AtB that are equal to one in case of, respectively, Added-to-Sell and Added-to-Buy recommendation changes. According to Womack (1996), stocks "added-to-buy" or "added-to-sell" lists record the strongest market reactions. We then focus on our main objective and we test several models to discern the effect of valuation methods in terms of market reaction.

The theory of finance suggests that there are "superior" methods, conceptually "correct" since they are based on the discounted cash flows approach; while there are other heuristic methods (e.g. the approach using market ratios) lacking robust theoretical foundations, and thus considered "incorrect". Despite this, the latter ones are frequently used in practice. Among the methods used by analysts in our sample, the financial one represents more than a half of the overall observations (54.2\%), followed by market ratios (31.8\%), net assets-based (10.3\%), mixed (2.4\%) and income-based (1.4\%) methods. We first assess whether the market reacts differently to reports based on different kind of valuation methods. We define a set of dummy variables that take the value of one when the primary valuation method in the report is, alternatively, the Net Assets (NA), Income (I), Mixed (MX), Market Ratios (MR) or Financial (F) method. Differently from Asquith et al. (2005), our model allows us to control for the potential asymmetries in the market reaction, depending on the recommendation type. Since downgrades and upgrades effects could offset each other, we include in our regression interaction variables. These variables allow us to capture the "valuation method effect", conditionally on the recommendation type (downgrade/upgrade). In particular, we consider Equation 1:

$$
\begin{gathered}
A R_{i}=\alpha_{1} R d_{i} \times F_{i}+\alpha_{2} R d_{i} \times M X_{i}+\alpha_{3} R d_{i} \times N A_{i}+\alpha_{4} R d_{i} \times I_{i}+\alpha_{5} R d_{i} \times M R_{i}+\alpha_{6} R u_{i} \times F_{i}+\alpha_{7} R u_{i} \times M X_{i}+ \\
+\alpha_{8} R u_{i} \times N A_{i}+\alpha_{9} R u_{i} \times I_{i}+\alpha_{10} R u_{i} \times M R_{i}+\varepsilon_{i}
\end{gathered}
$$

If the markets were in line with the classical finance, we would find a significantly greater reaction for the financial methods rather than other valuation methods. However, the behavioural finance literature shows that investors often prefer to follow valuation rules they are more comfortable with, including heuristic approaches. Moreover, the fact that the financial method only accounts for 54\% of the methods used seems to suggest that at least analysts are not perfectly in line with the traditional approach to finance. Therefore, we do not have an ex-ante position towards the market reaction in case of different valuation methods. However, we think that there could be asymmetric reactions in correspondence of upgrades or downgrades. The analysts are frequently accused of their excess of optimism. We could thus argue that investors require more original and substantial estimates to justify and support positive estimations. By definition, methods based on fundamental analysis need a set of original estimates of parameters and cash flows to be fed. Thus, we expect that the market reacts more when the upgrades are backed by fundamental methods.

Following this reasoning, we introduce a second research question based on the assumption that if the market significantly reacts to a set of different valuation methods, then the analysts employing more than one method in their reports should exert a greater effect on the market.

The underlying intuition is that analysts using a combination of different valuation techniques (the main one followed and checked with secondary methods) are giving more relevant information to the market and are better supporting their forecasts and recommendations.

The traditional approach to finance claims that the only method for firm valuation that is appropriate is the one based on discounted cash flow. Thus, there is no need for secondary methods that, by definition, are second best and instead of supporting the main method could bias its results.

The behavioural finance literature, instead, points out that investors tend to naively think that more methods can lead to a better valuation. The intuition is that they could think that while a single method can be wrong, using more than one method can reduce the probability of error.

In this framework, these reports are perceived as more grounded and are expected to have a greater impact on the market than those based on just one method. We call this effect "cross reinforcing methods effect" and we argue that it could also depend on the type of recommendation revision. We use Equation 2 to test this hypothesis. In particular, Equation 2 includes the interaction variables between the recommendation revisions and the number of evaluation methods used in the reports to control, again, for potential asymmetries in the market reaction:

$$
\begin{gathered}
A R_{i}=\alpha_{1} R d_{i} \times S M_{i}+\alpha_{2} R u_{i} \times S M_{i}+\alpha_{3} R d_{i} \times \\
M M_{i}+\alpha_{4} R u_{i} \times M M_{i}+\varepsilon_{i}
\end{gathered}
$$

where $S M_{i}$ and $M M_{i}$ are dummy variables indicating the use of a single (Single Method) or multiple methods (Multiple Methods).

\section{EMPIRICAL RESULTS}

\subsection{Market reaction following recommendation and target price revisions}

In Table 1 , we show the market reaction to the recommendation revisions. The results reported in column 1 are in line with theory and intuition: in case of downgrade, the abnormal return is negative $(-0.853 \%)$, while the opposite happens in case of upgrade $(0.648 \%)$. In magnitude, the market reaction to downgrades is larger than the market reaction to upgrades, in line with previous findings. ${ }^{8}$

8 We also re-estimate the model including several control variables. In particular, we take into account the size effect, the number of reports issued particular, we take into account the size effect, the number of reports issued by analysts, and the potential confounding effects (such as earnings releases) in the window $[-10 ;+10]$ around the report date. However, none of these 
Table 1. Abnormal returns following recommendation changes

\begin{tabular}{|c|c|c|c|c|c|}
\hline Description & Variable & \multicolumn{2}{|c|}{ Model 1} & \multicolumn{2}{|c|}{ Model 2} \\
\hline \multirow{2}{*}{ Recommendation downgrade } & \multirow{2}{*}{$\mathrm{Rd}$} & -0.853 & $* \ldots$ & -0.832 & 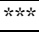 \\
\hline & & $(0.086)$ & & $(0.085)$ & \\
\hline \multirow{2}{*}{ Recommendation upgrade } & \multirow{2}{*}{$\mathrm{Ru}$} & 0.648 & $* * *$ & 0.632 & 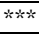 \\
\hline & & $(0.078)$ & & $(0.110)$ & \\
\hline \multirow{2}{*}{ Added-to-Sell } & \multirow{2}{*}{ AtS } & - & & -1.096 & $* *$ \\
\hline & & & & $(0.436)$ & \\
\hline \multirow{2}{*}{ Added-to-Buy } & \multirow{2}{*}{ AtB } & - & & 0.667 & 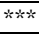 \\
\hline & & & & $(0.109)$ & \\
\hline Regression F-test & & 86.073 & 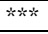 & 43.228 & 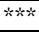 \\
\hline $\mathrm{N}$ & & 2811 & & 2811 & \\
\hline R-squared & & 0.058 & & 0.058 & \\
\hline
\end{tabular}

Note: $* * * *$, and $*$ indicate statistically significance at 1\%, 5\%, and $10 \%$ level, respectively. Robust Standard Errors in parentheses.

Table 2. Abnormal returns following target price changes and joint target prices/recommendations revisions

\begin{tabular}{|c|c|c|c|c|c|}
\hline Description & Variable & \multicolumn{2}{|c|}{ Model 3} & \multicolumn{2}{|c|}{ Model 4} \\
\hline \multirow{2}{*}{ Target price downgrade } & \multirow{2}{*}{ TPd } & -0.885 & 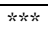 & - & \\
\hline & & $(0.171)$ & & & \\
\hline \multirow{2}{*}{ Target price upgrade } & \multirow{2}{*}{$\mathrm{TPu}$} & 0.305 & 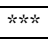 & - & \\
\hline & & $(0.106)$ & & & \\
\hline \multirow{2}{*}{ Recommendation downgrade \& target price downgrade } & \multirow{2}{*}{ Rd TPd } & - & & -1.280 & $* * *$ \\
\hline & & & & $(0.185)$ & \\
\hline \multirow{2}{*}{ Recommendation downgrade \& target price upgrade } & \multirow{2}{*}{$\mathrm{Rd} \mathrm{TPu}$} & - & & -0.475 & $*$ \\
\hline & & & & $(0.256)$ & \\
\hline \multirow{2}{*}{ Recommendation upgrade \& target price downgrade } & \multirow{2}{*}{$\mathrm{Ru} \mathrm{TPd}$} & - & & 0.630 & \\
\hline & & & & $(0.399)$ & \\
\hline \multirow{2}{*}{ Recommendation upgrade \& target price upgrade } & \multirow{2}{*}{$\mathrm{Ru} \mathrm{Tpu}$} & - & & 0.588 & **\% \\
\hline & & & & $(0.109)$ & \\
\hline Regression F-test & & 21.556 & 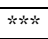 & 21.754 & 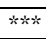 \\
\hline $\mathrm{N}$ & & 1189 & & 1189 & \\
\hline R-squared & & 0.035 & & 0.068 & \\
\hline
\end{tabular}

Notes: $* * * * *$, and $*$ indicate statistically significance at $1 \%, 5 \%$, and $10 \%$ level, respectively. Robust SEs in parentheses.

As a matter of fact, our preliminary results mirror those of Cervellati et al. (2007a) that are based on reports issued up to July 2005. However, compared to Belcredi et al. (2003), we find a lower market reaction, in magnitude, both for upgrades and downgrades. A possible explanation is that while they analyse the reports issued between September 1999 and March 2002, i.e. the Internet bubble period on the Italian market, our research includes a broader period, including both bear and bull markets. ${ }^{9}$

Furthermore, we provide evidence that extreme revisions have a larger impact on the market. While the difference between upgrade and added-to-buy is not economically relevant $(0.632 \%$ vs. $0.667 \%$ ), the market reaction following an added-to-sell recommendation is definitely larger than the one associated with a generic downgrade $(-1.096 \% v s .-0.832 \%){ }^{10}$ The rational explanation to this evidence is that since negative extreme recommendation revisions are rare, the value conveyed to the market is higher, with a consequent larger price reaction. From a behavioural point of view, instead, this is a consequence of investors' loss aversion (Kahneman \& Tversky, 1979). It is worth noting that of the overall 1,481 downgrades, there are only 118 added-to-sell revisions, i.e. the $8 \%$ of the total, while of the 1,330 upgrades, added-to-buy

\footnotetext{
9 Our dataset refers to a ten year period spanning over (at least) two complete market cycles. Thus, it is important to check if our results are stable over time. To test for year-effect, we consider a regression with year dummies. A joint Wald test indicates the presence of a year-effect $(F-s t a t=1.6743$, $\mathrm{p}$ -
value $=0.031$ ). In particular, the market reaction to downgrades and upgrades value $=0.031$ ). In particular, the market reaction to downgrades and upgrades
tends to be quite stable in the slowly growing market period 2002-2006, while tends to be quite stable in the slowly growing market period 2002-2006, while
during crisis periods - like the Internet bubble years (1999-2001) and the during crisis periods - like the Internet bubble years (1999-2001)
recent crisis (2007-2009) - the market reaction tends to be amplified. recent crisis (2007-2009) - the market reaction tends to be amplified.
10 Our results are in line with the quoted studies on the Italian case.
}

changes represent the $46 \%$ of the total number of revisions. This evidence can probably explain the greater market reaction following the rare added-tosell revisions compared to added-to-buy changes. In Table 2, we show the market reaction to target price changes. ${ }^{11}$

Some models are based on fewer observations because not all reports include all information needed in the analysis. Only models based on the same number of observations are directly comparable. If two models are based on different observations, they can be compared only on qualitative terms. As expected, the effect of a target price downgrade is negative $(-0.885 \%)$, while the abnormal return following a target price upgrade is positive $(0.305 \%)$, but of lower magnitude. While the frequency of target price upgrades $(52.5 \%)$ is slightly higher than the one of downgrades (47.5\%), the average price increase in case of the upgrade is about $13 \%$ versus an average price reduction of $-21 \%$ in case of the downgrade. This evidence could explain the stronger market reaction in case of target price downgrade. Model 4 provides information on the investor reaction when revisions in recommendations and target prices are reinforcing or countervailing each other. Consistently with Brav and Lehavy (2003), abnormal returns associated with recommendation upgrades (downgrades) are larger when such revisions coincide with positive (negative) target price revisions. In the case of a double downgrade (37.7\% of the total observations in regression 4), we observe

${ }^{11}$ Some models are based on fewer observations because not all reports include all information needed in the analysis. Only models based on the same number of observation are directly comparable. If two models are based on different observations, they can be compared only on qualitative terms. 
the strongest negative market reaction (-1.28\%). If a report features a recommendation downgrade and a target price upgrade ( $14 \%$ of the cases), instead, the effect is still negative but reduced in magnitude (-0.475\%). Thus, the effect of the recommendation downgrade prevails on the one caused by the target price upgrade. If a recommendation upgrade is accompanied by a target price downgrade (9.8\% of the observations), the market reaction is not statistically different from zero, i.e., the two effects counterbalance each other. Finally, in the case of double upgrade $(38.5 \%$ of the cases), the market reaction is positive and statistically significant. We highlight that, even if the majority of the cases include a coherent signal (i.e., target price revision and recommendation in the same direction), the frequency of contrasts is not negligible. These results indicate that the degree of the recommendation revision conveys information to the market regarding analysts' uncertainty about the overall forecast of the company prospects.

\subsection{The informative value of the valuation methods}

Table 3 shows the results of Models 5 and 6, which refer to Equations 1 and 2 respectively.

Table 3. Abnormal returns by valuation method

\begin{tabular}{|c|c|c|c|c|c|}
\hline Description & Variable & \multicolumn{2}{|c|}{ Model 5} & \multicolumn{2}{|c|}{ Model 6} \\
\hline \multirow{2}{*}{ Recommendation downgrade \& financial methods } & \multirow{2}{*}{ Rd F } & -0.748 & 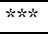 & - & \\
\hline & & $(0.137)$ & & & \\
\hline \multirow{2}{*}{ Recommendation downgrade \& mixed methods } & \multirow{2}{*}{ Rd MX } & -0.575 & & - & \\
\hline & & $(0.382)$ & & & \\
\hline \multirow{2}{*}{ Recommendation downgrade \& net asset methods } & \multirow{2}{*}{ Rd NA } & -0.799 & 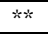 & - & \\
\hline & & $(0.383)$ & & & \\
\hline \multirow{2}{*}{ Recommendation downgrade \& income methods } & \multirow{2}{*}{ Rd I } & 1.048 & & - & \\
\hline & & $(0.988)$ & & & \\
\hline \multirow{2}{*}{ Recommendation downgrade \& market ratios } & \multirow{2}{*}{ Rd MR } & -0.676 & 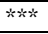 & - & \\
\hline & & $(0.187)$ & & & \\
\hline \multirow{2}{*}{ Recommendation upgrade \& financial methods } & \multirow{2}{*}{$\mathrm{Ru} \mathrm{F}$} & 0.454 & *出* & - & \\
\hline & & $(0.137)$ & & & \\
\hline \multirow{2}{*}{ Recommendation upgrade \& mixed methods } & \multirow{2}{*}{$\mathrm{Ru} \mathrm{MX}$} & 0.531 & & - & \\
\hline & & $(0.497)$ & & & \\
\hline \multirow{2}{*}{ Recommendation upgrade \& net asset methods } & \multirow{2}{*}{ Ru NA } & 0.537 & ** & - & \\
\hline & & $(0.238)$ & & & \\
\hline \multirow{2}{*}{ Recommendation upgrade \& income methods } & \multirow{2}{*}{$\mathrm{Ru} I$} & 0.508 & & - & \\
\hline & & $(0.612)$ & & & \\
\hline \multirow{2}{*}{ Recommendation upgrade \& market ratios } & \multirow{2}{*}{$\mathrm{Ru} \mathrm{MR}$} & 0.964 & **** & - & \\
\hline & & $(0.192)$ & & & \\
\hline \multirow{2}{*}{ Recommendation downgrade \& one method } & \multirow{2}{*}{ Rd SM } & - & & -0.693 & 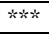 \\
\hline & & & & $(0.122)$ & \\
\hline \multirow{2}{*}{ Recommendation upgrade \& one method } & \multirow{2}{*}{$\mathrm{Ru} \mathrm{SM}$} & - & & 0.633 & $* * *$ \\
\hline & & & & $(0.115)$ & \\
\hline \multirow{2}{*}{ Recommendation downgrade \& more than one method } & \multirow{2}{*}{ Rd MM } & - & & -0.927 & $\frac{1}{n}$ \\
\hline & & & & $(0.179)$ & \\
\hline \multirow{2}{*}{ Recommendation upgrade \& more the one method } & \multirow{2}{*}{ Ru MM } & - & & 0.786 & $\% * *$ \\
\hline & & & & $(0.158)$ & \\
\hline Regression Wald test & & 9.334 & $* * *$ & 28.982 & $\% * *$ \\
\hline $\mathrm{N}$ & & 1439 & & 1829 & \\
\hline R-squared & & 0.061 & & 0.060 & \\
\hline
\end{tabular}

Model 5 refers to the market reaction to different valuation methods used by the analysts. Our results are different from previous findings by Asquith et al. (2005) in that we find a statistically significant "method effect". As re-parameterization of Model 5 in terms of differences with respect to a base case (e.g. recommendation downgrade and financial methods) allows us to test for this effect, i.e. if the difference between methods is statistically significant. A joint Wald test leads us to strongly reject the null hypothesis of the inexistence of a method effect (F-stat $=14.316, \quad$-value $<0.001$ ) Thus, the specific method used by analysts plays an important role in explaining abnormal returns. In case of a downgrade, financial and net assets-based methods have the higher effect on the market (respectively $-0.748 \%$ and $-0.799 \%$ ), with respect to a valuation with market ratios $(-0.676 \%)$, while mixed and income-based methods do not have a statistically significant effect. $^{12}$ For upgrades, instead, while the latter two methods remain not significant, the valuation method that uses market ratios is associated with the larger market reaction (0.964\%) compared to the financial $(0.454 \%)$ and net assets-based $(0.537 \%)$ methods. The market reaction is higher in magnitude for downgrade rather than upgrades, with the only exception of the market ratios method. This result is at odds with our hypothesis stating that the market should rely more on fundamental methods because they are fed by a larger and more original information set.

Model 6 refers to Equation 2. In line with our expectations, we find a larger market reaction when analysts use multiple methods to assess the value of a company. A reasonable explanation could be that investors trust more those analysts using more methods to support their recommendation. If this is

${ }^{12}$ However, the results for the income and mixed methods should be taken with caution given the low number of observations associated to them. 
true, then it can be debated whether this investors' behaviour can be considered rational or not Traditional finance claims that the best valuation method is the Discounted Cash Flow approach. Thus, there should be no need of alternative methods that, by definition, should be considered as second best. From a psychological point of view, instead, investors may feel better knowing that analysts use several methods to support their view. The behavioural finance literature (Shefrin, 2006) highlights that often analysts use multiple valuation methods to find the target price that is an average of the results found with the distinct approaches. This is a practice known as " $1 / \mathrm{n}$ heuristic", an example of a naïve approach to valuation. To sum up, our empirical evidence shows that there's a "method effect". This means that although the traditional financial theory indicates just one category of methods as the best one, the market gives credit to the different valuation techniques (see Model 5). As a consequence of this market behaviour, reports using more than one method benefit of a sort of "cross reinforcing methods effect" and, thus, they are considered as more informative.

\section{CONCLUSION}

We examine the informative value for the market of financial analysts' reports. We show how investors in the Italian stock exchange react to recommendations and target prices revisions. Then, we highlight that the market is able to recognize the informative content of the reports, reacting in a distinct way to the different valuation methods used by analysts. In correspondence of downgrades (upgrades) of both investment recommendations and target prices, we find statistically significant negative (positive) abnormal returns. In particular, the market reaction to downgrades is larger than the market reaction to upgrades. The short-term market reaction following a recommendation change is also related to the strength of the revision. As a matter of fact, stocks "added-to-buy" or "added-to-sell" lists record the strongest market reactions. However, extreme downgrades have the greatest impact from an economic point of view. This evidence suggests that the market interprets the extreme negative information as more informative since they are very rare. These results hold when we substitute the target price revision with the expected returns, measured as the relative difference between the target and current market price. In contrast with previous findings in the literature (see Asquith et al., 2005), we find a "method effect", meaning that the market does react differently depending on the valuation method used by the analyst. Furthermore, we find a "cross reinforcing methods effect", indicating that investors trust more those reports issuing recommendations based on several methods rather than those based on just one method. This evidence is independent of the type of recommendation revision (upgrade or downgrade). In addition, conditionally on the recommendation changes, the market reacts differently to distinct types of valuation methods. In the case of a downgrade, financial and net asset-based methods have the greatest impact on the market, with respect to market ratios methods. On the contrary, mixed and income methods do not have any statistically significant effect. For upgrades, instead, while the latter two methods remain not significant, the valuation method using market ratios is associated with the largest market reaction when compared to the financial and net asset-based methods.

A possible limitation of the present study is that it is based on data that are not very recent. However, as mentioned, since the data were hand collected from analysts' reports on the Italian stock exchange website, it takes several years to collect and catalogue them. In addition, in recent years the number of reports available in the above-mentioned website decreased substantially, thus apparently not being representative anymore of the overall analysts' reports on companies listed in Italy.

The other potential limitation of our study is that it focuses on the Italian stock exchange. While this is a limit on one hand, on the other hand, as we clarified above, Italy is a unique case in this respect because by regulation the reports should be freely and publicly available. This allowed us to extract several pieces of information, including the valuation methods used by sell-side analysts that are usually not available in commercial datasets.

In future research, it would be interesting and useful to update the present study including more recent analysts' reports, but also to include other countries, to perform a cross-country analysis and verify if there are differences among countries in terms of market reaction to different valuation methods used.

\section{REFERENCES}

1. Abarbanell, J., Lanen, W., \& Verrecchia, R. (1995). Analysts' forecasts as proxies for investor beliefs in empirical research. Journal of Accounting and Economics, 20(1), 31-60. https://doi.org/10.1016/0165-4101(94)00392-I

2. Asquith, P., Mikhail, M., \& Au, A. (2005). Information content of equity analyst reports. Journal of Financial Economics, 75(2), 245-282. https://doi.org/10.1016/j.jfineco.2004.01.002

3. Barber, B., \& Odean, T. (2007). All that glitters: The effect of attention and news on the buying behavior of individual and institutional investors. Review of Financial Studies, 21(2), 785-818. https://doi.org/10.1093/rfs/hhm079

4. Barber, B., Lehavy, R., McNichols, M., \& Trueman, B. (2001). Can investors profit from the prophets? Security analyst recommendations and stock returns. The Journal of Finance, 56(2), 531-563. https://doi.org/10.1111/00221082.00336

5. Belcredi, M., Bozzi, S., \& Rigamonti, S. (2003). The impact of research reports on stock prices in Italy (Working Paper, EFMA 2003 Helsinki Meetings). Retrieved from https://doi.org/10.2139/ssrn.391680

6. Bilinski, P., Lyssimachou, D., \& Walker, M. (2013). Target price accuracy: International evidence. The Accounting Review, 88(3), 825-851. https://doi.org/10.2308/accr-50378

7. Bonini, S., \& Kerl, A. (2012). Private information, subjective valuation and target price accuracy. Retrieved from https://doi.org/10.2139/ssrn.2168856 
8. Bonini, S., Zanetti, L., Bianchini, R., \& Salvi, A. (2010). Target price accuracy in equity research. Journal of Business Finance \& Accounting, 37(9-10), 1177-1217. https://doi.org/10.1111/j.1468-5957.2010.02209.x

9. Bradshaw, M. (2002). The use of target prices to justify sell-side analysts' stock recommendations. Accounting Horizons, 16(1), 27-41. https://doi.org/10.1007/s11142-012-9216-5

10. Bradshaw, M., Brown, L., \& Huang, K. (2012). Do sell-side analysts exhibit differential target price forecasting ability? Review of Accounting Studies, 18(4), 930-955. https://doi.org/10.1007/s11142-012-9216-5

11. Brav, A., \& Lehavy, R. (2003). An empirical analysis of analysts' target prices: Short-term informativeness and long-term dynamics. The Journal of Finance, 58(5), 1933-1967. https://doi.org/10.1111/1540-6261.00593

12. Brown, L. D., Call, A. C., Clement, M. B., \& Sharp, N. Y. (2014). Skin in the game: The inputs and incentives that shape buy-side analysts' stock recommendations (Working Paper). Retrieved from https://pdfs.semanticscholar.org/5ef7/ aa16e4699d1a757bc01de0b5b9b0ee7afef8.pdf

13. Brown, L. D., Call, A. C., Clement, M. B., \& Sharp, N. Y. (2015). Inside the "black box" of sell-side financial analysts. Journal of Accounting Research, 53(1), 1-47. https://doi.org/10.1111/1475-679X.12067

14. Campbell, J. Y., Lo, A. W., \& MacKinlay, A. C. (1997). The econometrics of financial markets. https://doi.org/ $10.1515 / 9781400830213$

15. Carhart, M. M. (1997). On persistence in mutual fund performance. The Journal of Finance, 52(1), 57-82. https://doi.org/10.1111/j.1540-6261.1997.tb03808.x

16. Cavezzali, E., Rigoni, U., \& Nathan, S. (2015). Valuation method used by financial analysts and target price accuracy. Retrieved from http://www.fmaconferences.org/Venice/Papers/Cavezzali_Rigoni_Nathan_AnalystsPaper_Decemb er_1_2014.pdf

17. Cervellati, E. M. (2012). Analysts' distorted valuation of hi-tech stocks. Corporate Ownership \& Control, 10(1-3), 380-395. https://doi.org/10.22495/cocv10i1c3art6

18. Cervellati, E. M., \& Piras, L. (2012). Inform and deform: Do financial analysts mean what they say? Sumy, Ukraine: Virtus Interpress.

19. Cervellati, E. M., Della Bina, A. C. F., \& Pattitoni, P. (2007a). Equity research credibility in the Italian stock market [Special Issue]. Corporate Ownership \& Control, 4(4-4), 59-77. https://doi.org/10.22495/cocv4i4c4p6

20. Cervellati, E. M., Della Bina, A. C. F., \& Pattitoni, P. (2007b). Investment value of recommendations in the Italian stock exchange [Special Issue]. Corporate Ownership \& Control, 4(4-4), 78-91. https://doi.org/10.22495/cocv4i4c4p7

21. Cervellati, E. M., Della Bina, A. C. F., \& Pattitoni, P. (2008). The efficiency of the Italian stock exchange: market reaction following changes in recommendations [Special issue]. Corporate Ownership \& Control, 5(2-4), 434-448. https://doi.org/10.22495/cocv5i2c4p5

22. Clement, M. B. (1999). Analyst forecast accuracy: Do ability, resources, and portfolio complexity matter? Journal of Accounting and Economics, 27(3), 285-303. https://doi.org/10.1016/S0165-4101(99)00013-0

23. Clement, M. B., \& Tse, S. Y. (2003). Do investors respond to analysts' forecast revisions as if forecast accuracy is all that matters? The Accounting Review, 78(1), 227-249. https://doi.org/10.2308/accr.2003.78.1.227

24. De Vincentiis, P. (2010). Accuracy and bias of equity analysts in environment characterized by higher disclosure: Empirical evidence from the Italian market (EMFI Working Paper No. 3). Retrieved from https://papers.ssrn.com/sol3/papers.cfm?abstract_id=1590881

25. Demirakos, E., Strong, N., \& Walker, M. (2010). Does valuation model choice affect target price accuracy? European Accounting Review, 19(1), 35-72. https://doi.org/10.1080/09638180902990630

26. Dittmar, R. F., Kaul, G., \& Lei, Q. (2007). Momentum is not an anomaly. Retrieved from https://doi.org/10.2139/ ssrn. 1027057

27. Elgers, P., Lo, M., \& Pfeiffer, R. (2001). Delayed security price adjustments to financial analysts' forecasts of annual earnings. The Accounting Review, 76(4), 613-632. https://doi.org/10.2308/accr.2001.76.4.613

28. Fernandez, P. (2007). Company valuation methods: The most common errors in valuations (IESE Business School Working Paper No. 449). Retrieved from https://notendur.hi.is/ajonsson/kennsla2006/Valuation.pdf

29. Francis, J., \& Soffer, L. (1997). The relative informativeness of analysts' stock recommendations and earnings forecast revisions. Journal of Accounting Research, 35(2), 193-211. https://doi.org/10.2307/2491360

30. Frankel, R., Kothari, S. P., \& Weber, J. (2006). Determinants of the informativeness of analyst research. Journal of Accounting and Economics, 41(1-2), 29-54. https://doi.org/10.1016/j.jacceco.2005.10.004

31. Gleason, C. A., Johnson, W. B., \& Li, H. (2012). Valuation model use and the price target performance of sell-side equity analysts. Contemporary Accounting Research, 30(1), 80-115. https://doi.org/10.1111/j.1911-3846.2011. 01142.x

32. Gleason, C., \& Lee, C. (2000). Characteristics of price informative analyst forecasts. Retrieved from https://doi.org/10.2139/ssrn.254563

33. Gleason, C., \& Lee, C. (2003). Analyst forecast revisions and market price discovery. The Accounting Review, 78(1), 193-225. https://doi.org/10.2308/accr.2003.78.1.193

34. Hansen, R. S. (2015). What is the value of sell-side analysts? Evidence from coverage changes - A discussion. Journal of Accounting and Economics, 60(2-3), 58-64. https://doi.org/10.1016/j.jacceco.2015.08.005

35. Hashim, N. A., \& Strong, N. C. (2018). Do analysts' cash flow forecasts improve their target price accuracy? Contemporary Accounting Research, 35(4), 1816-1842. https://doi.org/10.1111/1911-3846.12369

36. Hobbs, J., \& Singh, V. (2015). A comparison of buy-side and sell-side analysts. Review of Financial Economics, 24, 42-51. https://doi.org/10.1016/j.rfe.2014.12.004

37. Hodge, F. (2003). Investors' perceptions of earnings quality, auditor independence, and the usefulness of audited financial information. Accounting Horizons, 17(s-1), 37-48. https://doi.org/10.2308/acch.2003.17.s-1.37

38. Jacob, J., Lys, T. Z., \& Neale, M. A. (1999). Expertise in forecasting performance of security analysts. Journal of Accounting and Economics, 28(1), 51-82. https://doi.org/10.1016/S0165-4101(99)00016-6

39. Jegadeesh, N., Kim, J., Krische, S. D., \& Lee, C. M. C. (2004). Analyzing the analysts: When do recommendations add value? The Journal of Finance, 59(3), 1083-1124. https://doi.org/10.1111/j.1540-6261.2004.00657.x

40. Jurgens, J. L. (2000). How do stock markets process analysts' recommendations? Retrieved from https://doi.org/ $10.2139 / \mathrm{ssrn} .167690$

41. Kahneman, D., \& Tversky, A. (1979). Prospect theory: An analysis of decision under risk. Econometrica, 47(2), 263-291.

42. Kerl, A. G. (2011). Target price accuracy. Business Research, 4(1), 74-96. https://doi.org/10.1007/BF03342727

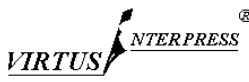


43. Kim, M. S., \& Zapatero, F. (2009). Rational bias and herding in analysts' recommendations (Marshall Research Paper Series, Working Paper FBE 08-10). Retrieved from ftp://ftp.cemfi.es/pdf/papers/wshop/Kim_Zapatero.pdf

44. Kucheev, Y., \& Sorensson, T. (2016). The origin of outperformance for stock recommendations by sell-side analysts. Retrieved from https://doi.org/10.2139/ssrn.2760277

45. Lys, T., \& Sohn, S. (1990). The association between revisions of financial analysts' earnings forecasts and securityprice changes. Journal of Accounting and Economics, 13(4), 341-363. https://doi.org/10.1016/0165-4101(90)90009-S

46. Merkley, K. J., Michaely, R., \& Pacelli, J. (2017a). Cultural diversity on Wall Street: Evidence from sell-side analysts' forecasts (Swiss Finance Institute Research Paper No. 19-07). Retrieved from https://papers.ssrn.com/sol3/ papers.cfm?abstract_id $=3068232$

47. Merkley, K., Michaely, R., \& Pacelli, J. (2017b). Does the scope of the sell-side analyst industry matter? An examination of bias, accuracy, and information content of analyst reports. The Journal of Finance, 72(3), 12851334. https://doi.org/10.1111/jofi.12485

48. Mikhail, M. B., Walther, B. R., \& Willis, R. H. (1997). Do security analysts improve their performance with experience? Journal of Accounting Research, 35, 131-157. https://doi.org/10.2307/2491458

49. Piras, L., Denti, O., \& Cervellati, E. M. (2012). Analyst reluctance in conveying negative information to the market. Journal of Governance and Regulation, 1(4), 7-22. https://doi.org/10.22495/jgr_v1_i4_p1

50. Shefrin, H. (2006). Behavioral corporate finance. New York, NY: McGraw-Hill.

51. Stickel, S. E. (1992). Reputation and performance among security analysts. The Journal of Finance, 47(5), 18111836. https://doi.org/10.1111/j.1540-6261.1992.tb04684.x

52. Stickel, S. E. (1995). The anatomy of the performance of buy and sell recommendations. Financial Analysts Journal, 51(5), 25-39. https://doi.org/10.2469/faj.v51.n5.1933

53. Williams, P., Moyes, G., \& Park, K. (1996). Factors affecting earnings forecast revisions for the buy-side and sellside analyst. Accounting Horizons, 10, 112-121.

54. Womack, K. L. (1996). Do brokerage analysts' recommendations have investment value? The Journal of Finance, 51(1), 137-167. https://doi.org/10.1111/j.1540-6261.1996.tb05205.x

55. Yin, Y., Peasnell, K., \& Hunt, H. G. (2016). How do sell-side analysts obtain price-earnings multiples to value firms? Accounting and Business Research, 48(1), 108-135. https://doi.org/10.1080/00014788.2016.1230486 